See Article page 1390.

\section{Commentary: Succeeding to prepare and preparing to succeed}

\author{
Shuab Omer, MD, ${ }^{\mathrm{a}, \mathrm{b}}$ Faisal H. Cheema, MD, ${ }^{\mathrm{a}, \mathrm{b}, \mathrm{c}}$ and \\ Keshava Rajagopal, $\mathrm{MD}, \mathrm{PhD}^{\mathrm{a}, \mathrm{b}}$
}

In this issue of the Journal, Coselli and colleagues ${ }^{1}$ report the results of proximal and arch aortic operations in patients who have undergone isolated previous coronary artery bypass grafting (CABG). While cardioaortic reoperations typically are greater risk than first-time operations, historically these risks simply have been acknowledged and consciously accepted, due to reoperations being the only available therapeutic options. However, with the application of endovascular approaches extending further proximally within the aorta, the benefits and risks of open approaches in the reoperative setting must be studied and interpreted in the context of catheter-based approaches. With this stated motivation in mind, the authors conducted their study.

The results are impressive. Nearly 3000 patients underwent proximal/arch aortic operations over approximately 20 years. Within this group, propensity-matched subset pairs of 252 patients (126 who previously underwent CABG, 126 who did not) were obtained. Operative and hospital mortality were $15.9 \%$ and $13.5 \%$ in the patients with a history of previous CABG, in contrast to $11.1 \%$ and $7.1 \%$ in the patients without a history of previous CABG; these were not statistically significant differences. With respect to morbid postoperative complications, the incidences of stroke were $6.3 \%$ versus $4.8 \%$, and the incidences of renal failure were $7.9 \%$ and $4.0 \%$, respectively, in the 2 groups; these also were not statistically significant differences.

\footnotetext{
From the ${ }^{\mathrm{a} D e p a r t m e n t}$ of Clinical Sciences, University of Houston College of Med-

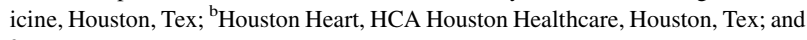
${ }^{\mathrm{c}} \mathrm{HCA}$ Research Institute, Nashville, Tenn.

Disclosures: The authors reported no conflicts of interest.

The Journal policy requires editors and reviewers to disclose conflicts of interest and to decline handling or reviewing manuscripts for which they may have a conflict of interest. The editors and reviewers of this article have no conflicts of interest.

Received for publication Nov 23, 2020; revisions received Nov 23, 2020; accepted for publication Nov 24, 2020; available ahead of print Dec 3, 2020.

Address for reprints: Keshava Rajagopal, MD, PhD, Department of Clinical Sciences, University of Houston College of Medicine, Houston Heart, HCA Houston Healthcare, 1200 Binz St, Suite 900, Houston, TX 77004 (E-mail: krajago2@central.uh. edu).

J Thorac Cardiovasc Surg 2022;164:1397-8

$0022-5223 / \$ 36.00$

Copyright (c) 2020 by The American Association for Thoracic Surgery

https://doi.org/10.1016/j.jtcvs.2020.11.114
}

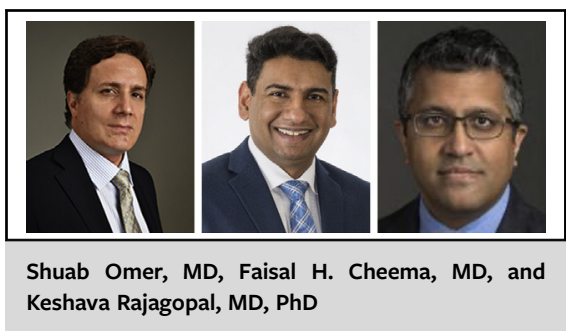

CENTRAL MESSAGE

Methodical preparation for

complex cardiac operations is

the foundation upon which the

best outcomes are built.

The propensity-matched patients were notably high-risk. Approximately $45 \%$ of patients underwent urgent or emergent operations, and consistent with this, $\sim 30 \%$ of patients underwent operations for acute type A aortic dissection. Finally, some operative differences were present between the propensity-matched subgroups. Patients without a previous history of CABG underwent more extensive aortic operations $(28.6 \%$ underwent aortic root replacement and $23.8 \%$ underwent total arch replacement, in contrast to $9.5 \%$ and $11.1 \%$, respectively, in those patients with a previous $\mathrm{CABG}$ history). However, patients with a previous history of $\mathrm{CABG}$, certainly unsurprisingly, underwent concomitant reoperative $\mathrm{CABG}$ at much greater rates ( $31.7 \%$, as opposed to $4.8 \%$ in patients without a previous history of $\mathrm{CABG}$ ).

In learning from a study with excellent results such as these, it is perhaps most important to identify the ingredients for success. In the case of this study, Dr Coselli's group has provided some important guidance. Coronary angiographic and thoracic computerized tomographic assessments were essential components of preoperative evaluation. Axillary or innominate arterial cannulation generally was employed, with the former being the preferred strategy in redo cases with aortic, bypass graft, or cardiac proximity to the sternum. Pre-sternotomy initiation of cardiopulmonary bypass and profound systemic hypothermia to $18^{\circ} \mathrm{C}-20^{\circ} \mathrm{C}$ was undertaken in cases of aortic proximity to the sternum, and saphenous vein harvesting was performed while preparing to open the sternum in patients with retrosternal patent left internal mammary artery bypass grafts. Cerebral protection was achieved using antegrade cerebral perfusion (ACP), typically under moderate systemic hypothermia $\left(\sim 24^{\circ} \mathrm{C}\right)$, 
with evolution from selective right-sided ACP via the right axillary or innominate artery, to routine bilateral ACP. Myocardial protection and management of patent in situ internal mammary arterial grafts was generally in keeping with common practices.

Each of the aforementioned practices is part of a systematic approach to prevention-and preparation for management, should it be needed-of adverse events. That is to say, extensive and thoughtful preparations were made to tackle challenging cases. To borrow from and modify Benjamin Franklin's quip, this study illustrates that "succeeding to prepare is preparing to succeed."

\section{Reference}

1. Preventza O, Amarasekara H, Price MD, Chatterjee S, Green SY, Woodside S, et al. Propensity score analysis in patients with and without previous isolated coronary artery bypass grafting who require proximal aortic and arch surgery. J Thorac Cardiovasc Surg. 2022;164:1390-6.e2.
See Article page 1390.

\section{Commentary: Is combining two high risk too high risk?}

\author{
Alexander Leung, $\mathrm{MD},{ }^{\mathrm{a}}$ and \\ Louis H. Stein, $\mathrm{MD}, \mathrm{PhD}^{\mathrm{b}}$
}

The impact of previous open-heart surgery on the expected outcome of a subsequent open-heart procedure is well characterized and well recognized by surgeons. ${ }^{1}$ The risk of injury to patent grafts and the challenges of myocardial protection can make previous CABG uniquely problematic. Clinical data have corroborated these concerns., ${ }^{2,3}$ Over the last decade, the operative risks associated with previous heart operation have persisted as the risk profile of those undergoing reoperation has increased. ${ }^{4,5}$

In this edition of the Journal, the group from Baylor draws upon their vast experience to quantitate the impact of previous CABG on proximal aortic surgery. ${ }^{6}$ They compare a group with previous $\mathrm{CABG}$ who underwent proximal aortic surgery with a propensity-matched group undergoing proximal aortic surgery without previous CABG. Previous CABG provides a unique problem for planning surgery of the ascending aorta, as proximal coronary bypass grafts are

\footnotetext{
From the a Division of Cardiothoracic Surgery, Department of Surgery, Albany Medical College; and ${ }^{\mathrm{b}}$ Division of Cardiothoracic Surgery, Albany Medical Center, Albany, NY.

Disclosures: The authors reported no conflicts of interest.

The Journal policy requires editors and reviewers to disclose conflicts of interest and to decline handling or reviewing manuscripts for which they may have a conflict of interest. The editors and reviewers of this article have no conflicts of interest.

Received for publication Nov 23, 2020; revisions received Nov 23, 2020; accepted for publication Nov 23, 2020; available ahead of print Dec 3, 2020.

Address for reprints: Louis H. Stein, MD, PhD, Division of Cardiothoracic Surgery, Albany Medical Center Surgeons Pavilion, 3rd Floor, 50 New Scotland Ave, Albany, NY 12208 (E-mail: steinl1@amc.edu).

J Thorac Cardiovasc Surg 2022;164:1398-9

$0022-5223 / \$ 36.00$

Copyright (c) 2020 by The American Association for Thoracic Surgery

https://doi.org/10.1016/j.jtcvs.2020.11.117
}

Check for updates

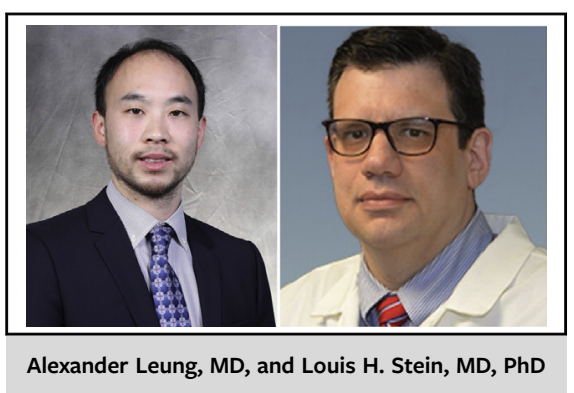

CENTRAL MESSAGE

In expert hands, previous CABG

does not increase the risk of

proximal aortic surgery, but the

devil still lies in the details.

most commonly anastomosed to the ascending aorta. The authors' data present a trend toward greater rates of operative mortality, 30-day mortality, and stroke but do not achieve statistical significance. The rates are similar to other case series. ${ }^{7}$ The rates of reoperation for bleeding and pericardial effusion requiring drainage, 2 common concerns for reoperative surgery, were no different between groups. The only significant difference between groups was the use of intra-aortic balloon pump. This likely relates to the difficulties of cardiac protection in the setting of a patent left internal mammary artery. Nevertheless, this did not result in a significant difference in mortality. Although falling just short of statistical significance $(P=.06)$, there was a trend toward an improved (nearly double) 10-year survival among the patients without CABG. Any difference here likely represents unaccounted comorbidities. The heterogeneity of procedures performed in this study is important to consider. The impact of a previous $\mathrm{CABG}$ on a hemiarch with root repair versus an arch repair is clearly different. The rubric of aortic procedure versus previous CABG anatomy results in many variations with too few cases 